\title{
Numerical Analysis of Magnetic Printing by Using a Perpendicular Anisotropy Master Medium
}

\author{
M. Nakazawa, H. Konishi, N. Sheeda, T. Komine, and R. Sugita \\ Ibaraki Univ., 4-12-1 Nakanarusawa-cho, Hitachi, Ibaraki 316-8511, Japan
}

\begin{abstract}
A perpendicular anisotropy master medium (PAMM) is proposed. The PAMM is composed of CoPt film with perpendicular magnetic anisotropy and large saturation magnetization. The magnetization distributions of PAMM and conventional master media (using an FeCo soft magnetic layer) were analyzed by using micromagnetic simulation. It was found that the peak-to-valley value of the recording field and the recording field gradient at the edge of the patterned magnetic film of PAMM were larger than those of the conventional master medium. Furthermore, the peak-to-valley value of the recording field and the recording field gradient of PAMM did not depend on the strength of the printing field. The printing characteristic of PAMM is twice that of the conventional master medium. Furthermore, the optimum printing field for PAMM is $1 \mathrm{kOe}$ lower than that of the conventional master medium. As a result, PAMM is expected to improve the printing characteristic of the bit printing method.
\end{abstract}

Key words: magnetic printing, perpendicular anisotropy master, servo signal

\section{垂直異方性マスター媒体を用いた磁気転写の数值解析}

中澤光貴 - 小西弘孝・Nurul Sheeda - 小峰啓史・杉田龍二

茨城大学工学部, 茨城県日立市中成沢町 4-12-1（广316-8511）

\section{1. はじめに}

ハードディスクの高記録密度化, 大容量化が進んでおり, サーボ 信号の高速, 高精度かつ安価な形成方法が課題となっている. これ らの課題を解決すべく磁気転写法が検討されている 1). 村田らは, ビット転写における転写特性が, 軟磁性膜で作製されたマスター 媒体（FeCo）の飽和磁化には依存せず，マスタ一磁性膜形状に依 る反磁場係数にのみ依存することを明らかにした. 同時に, 従来の マスター媒体では, 転写時において FeCoの飽和磁化が十分に活用 されていないことを指摘した ${ }^{2}$. 本研究では, 垂直磁気異方性を有 するマスター媒体(Perpendicular Anisotropy Master Medium, PAMM)を提案し，マスター磁生膜内の磁化分布及ひ磁性膜近傍に おける記録磁場分布をマイクロマグネティックシミュレーション により解析し, 従来マスター媒体と比較した.

\section{2. 垂直異方性マスター媒体}

本研究で提案する PAMMは垂直磁気異方性を有し, かつ飽和磁 化の大きな $\mathrm{CoPt}$ 薄膜で構成されている. パターニングされた $\mathrm{CoPt}$ 及び FeCo のヒステリシスループの模式図を Fig. 1 に示寸.

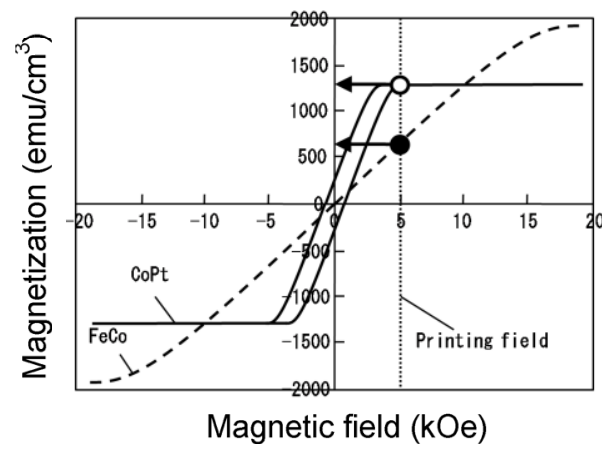

Fig. 1 Schematic perpendicular hysteresis loops of CoPt and $\mathrm{FeCo}$ patterned magnetic films.
パターニング形状は, $\mathrm{CoPt}, \mathrm{FeCo}$ 共に, ビット長及びトラック幅 方向のサイズがいずれも $100 \mathrm{~nm}$, 膜厚が $50 \mathrm{~nm}$ の磁生膜が, 間隔 $100 \mathrm{~nm}$ で2次元的に配置されており, $\mathrm{CoPt} の$ 垂直磁気異方性磁場 $H_{\mathrm{k}}$ が $5 \mathrm{kOe}$ 程度のものを想定した. ビット転写においては, 最適 転写磁場は記録層の保磁力程度の強さである ${ }^{3)}$. それゆえ, 記録層 保磁力が $5 \mathrm{kOe}$ 程度のハードディスクがスレーブ媒体である場合, Fig. 1 より, 飽和磁場が $17 \mathrm{kOe}$ と大きい FeCo マスター媒体にお いては, 最適転写磁場では飽和磁化の $1 / 3$ 程度しか磁化されない. 一方, $\mathrm{CoPt}$ の場合, 垂直磁気異方性のため飽和磁場が小さくなり, 最適転写磁場における磁化は, $\mathrm{FeCo}$ の約 2 倍になると予想される. マスター磁性膜の磁化が増大寸ることで転写特性の改善が期待で きる.

\section{3. シミュレーション方法}

ビット転写では，まずスレーブ媒体の垂直方向に初期磁場を印 加し, スレーブ媒体を一方向に磁化する. 次にマスター媒体を接触 させ, 初期磁場と反対向きに転写磁場を印加する. マスター磁生膜 接触部では磁場が強くなるため初期磁化が反転し, 非接触部では 磁場が弱くなり初期磁化が保存される. その結果, マスター媒体の パターンがスレーブ媒体に転写される.

シミュレーションモデルの上面図及び断面図を Fig. 2 に示寸. 解析には, マスター磁性膜パターン幅及び間隔が等しいマスター 媒体のみが存在する空間を想定した. マスター磁生膜の寸法は, ビ ット長及びトラック幅を $100 \mathrm{~nm}$, 膜厚を $50 \mathrm{~nm}$ とした. 磁性膜パ ターンには, $\mathrm{CoPt}$ 及び FeCo を想定し, それぞれの飽和磁化を 1300, $1900 \mathrm{emu} / \mathrm{cm}^{3}$ とした. また, CoPt は垂直磁気異方性を有す るものと仮定し, 異方性磁場の強さを 1 15 kOe の範囲で変化さ せた. また, hcp c 軸の配向角度分散 $\Delta \theta_{50}$ を $5 \mathrm{deg}$. とした. 交換ス ティフネス定数 $A$ は $1.0 \times 10^{-6} \mathrm{erg} / \mathrm{cm}$ とした. 計算領域は Fig. 2 における点線部分とし，これを $5 \mathrm{~nm} \times 5 \mathrm{~nm} \times 5 \mathrm{~nm}$ のセルに分割 し, $x$ 及び $y$ 方向に周期境界条件を適用した. 初期状態における磁 


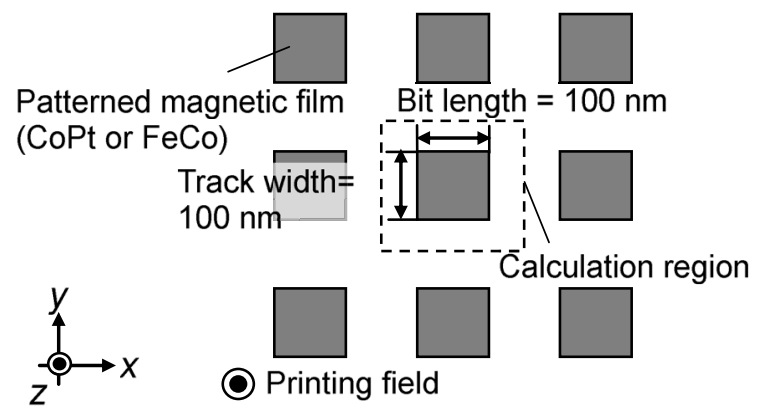

(a) Top view

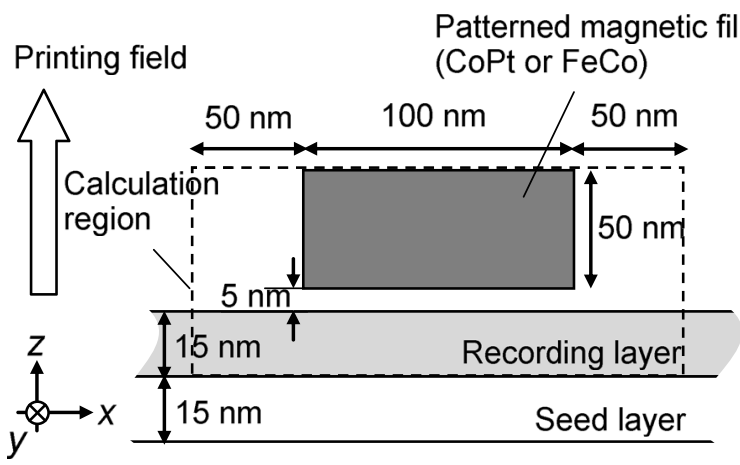

(b) Cross-section

Fig. 2 Simulation model.

化は, 全て転写磁場印加方向に向いているものとして計算を行っ た. 媒体膜面垂直方向に転写磁場を印加し, CoPt の垂直磁気異方 性及び転写磁場が磁性膜内の磁化分布, 及び記録磁場に与える影 響を調べ, $\mathrm{FeCo}$ 磁生膜の場合と比較した.

磁化の計算には LLG 方程式を用いた ${ }^{4}$. 磁気転写におい て記録磁場印加時間は数秒程度であり, ヘッド記録とは異 なり静的な磁化状態とみなせるため, 平衡状態をLLG方程 式により求めた. ダンピング定数を 1.0 , ジャイロ磁気定数 を $1.76 \times 10^{7} \mathrm{~Hz} / \mathrm{Oe}$ とし, LLG 方程式における $|\mathbf{M} \times \mathbf{H}|$ の最 大值が $1.0 \times 10^{2} \mathrm{erg} / \mathrm{cm}^{3}$ 以下となった磁化分布を平衡状態 とみなした.このとき, 磁化の変化は $1 \mathrm{memu} / \mathrm{cm}^{3}$ 以下で あった. マスター磁性膜が記録層中央部に作る記録磁場を 計算し, 比較を行った.

\section{4. シミュレーション結果及び考察}

\section{1 マスター磁性膜の垂直磁気異方性が磁化及び記録磁場 に及ぼす影響}

転写磁場を $5 \mathrm{kOe}$ とした場合の, $\mathrm{CoPt}\left(H_{\mathrm{k}}=15 \mathrm{kOe}\right)$ 及び $\mathrm{FeCo}$ 磁性膜内の磁化分布を Fig. 3(a)及び(b)に示寸. 磁化分布は, 各々 の飽和磁化で規格化し, 矢印で表現した. また, Fig. 3 の上部はマ スタ一磁性膜トラック中心部 $(x-z$ 面), 下部は記録層対向面 $(x-y$ 面ににおける磁化分布である. Fig. 3 より,$x-z$ 面の CoPt 磁生膜内 の磁化は, $\mathrm{FeCo}$ 磁性膜内のそれと異なり, 磁場印加方向に向くこ とがわかる. 記録層対向面における磁化分布に注目寸ると, $\mathrm{FeCo}$ 磁生膜では磁化が中心で渦を巻く構造になっていることがわかる. 我々が以前に行った研究においても, FeCo 磁性膜内の記録 層対向面における磁化分布は渦状構造であり, 今回得られ

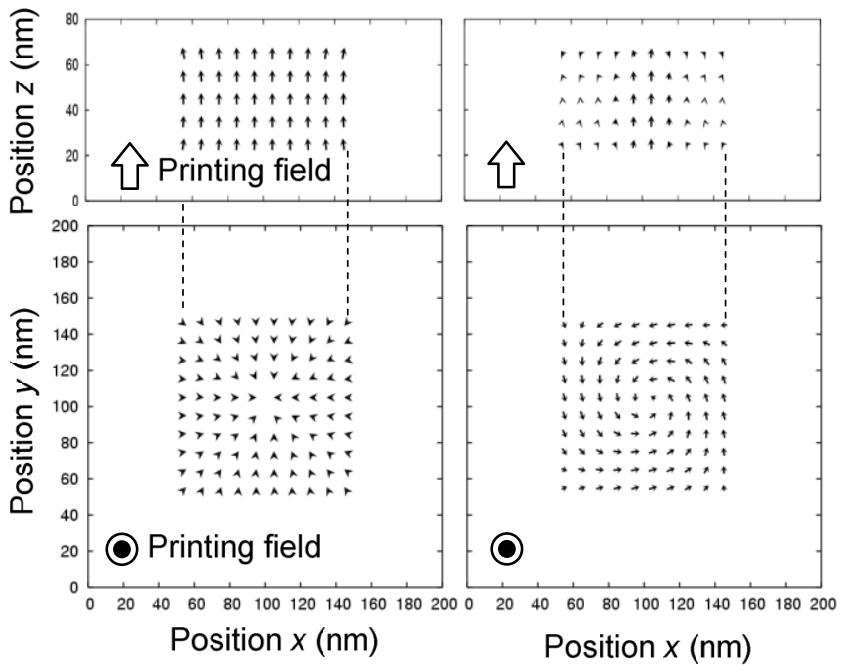

(a) $\operatorname{CoPt}\left(H_{\mathrm{k}}=15 \mathrm{kOe}\right)$

(b) $\mathrm{FeCo}$

Fig. 3 Magnetization distributions at the center of the track (upper panel) and on the surface of a patterned film (lower panel) in the case of (a) $\operatorname{CoPt}\left(H_{\mathrm{k}}=15 \mathrm{kOe}\right)$ and (b) FeCo.

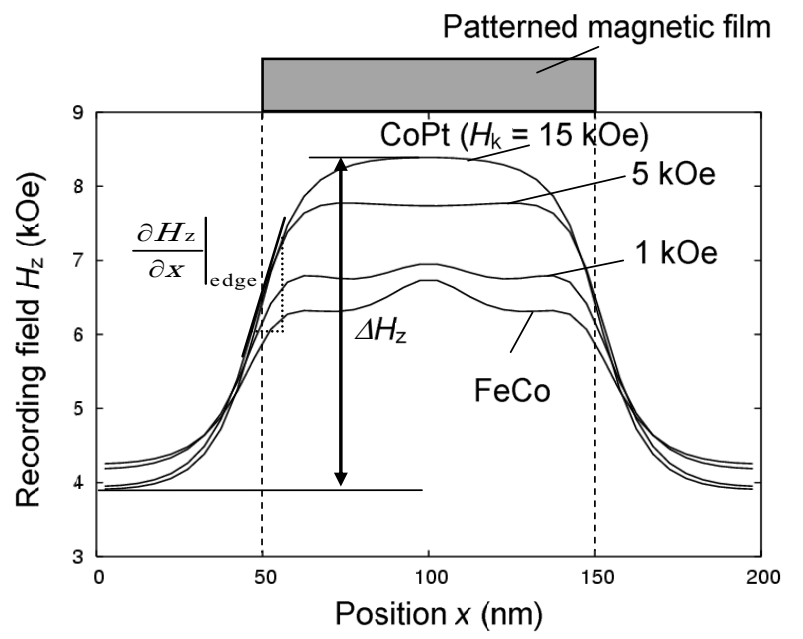

Fig. 4 Recording field distributions at the center of the track in various anisotropic fields.

た磁化分布は以前に報告した磁化分布と定性的に一致して いる ${ }^{4}$. 一方, $\mathrm{CoPt}$ 磁生膜では磁化が中心を向く構造であるが, 磁化の面内成分は小さい，

次に, $\mathrm{CoPt}\left(H_{\mathrm{k}}=1 \sim 15 \mathrm{kOe}\right)$ 及び $\mathrm{FeCo}$ マスター磁生膜に $5 \mathrm{kOe}$ の転写磁場を印加した場合の, 記蜍㶌場の $z$ 成分 $H_{z}$ を Fig. 4 亿示 寸. なお，記録磁場分布は，記録層膜厚方向中央部のトラック中心 部における值をプロットした. Fig. 4 より, $H_{\mathrm{k}}$ が $1 \mathrm{kOe}$ の CoPt 及 び $\mathrm{FeCo}$ 磁性膜の記録磁場分布はあまり変わらないが, $\mathrm{CoPt}$ 膜で は $H_{\mathrm{k}}$ が大きくなるに伴い, $H_{\mathrm{z}}$ の最大值が増加し, 最小值が減少す ることがわかる. Figs. 3 及び 4 から, $\mathrm{CoPt}$ 磁性膜の垂直磁気異方 性によって記録磁場が増大寸ることがわかる。

ビット転写では, 記録磁場の最大值と最小值の差, 及びマスター 磁性膜エッジ部の磁場勾配が転写特性に影響を及ぼす. $H_{z}$ の最大 值と最小值の差を $\Delta H_{z}$, マスター磁性膜エッジ部における記録磁 場の傾きを $\partial H_{z} /\left.\partial x\right|_{\text {edge }}$ として, Fig. 5 に $\Delta H_{z}$ 及び $\partial H_{z} /\left.\partial x\right|_{\text {edge }}$ の 


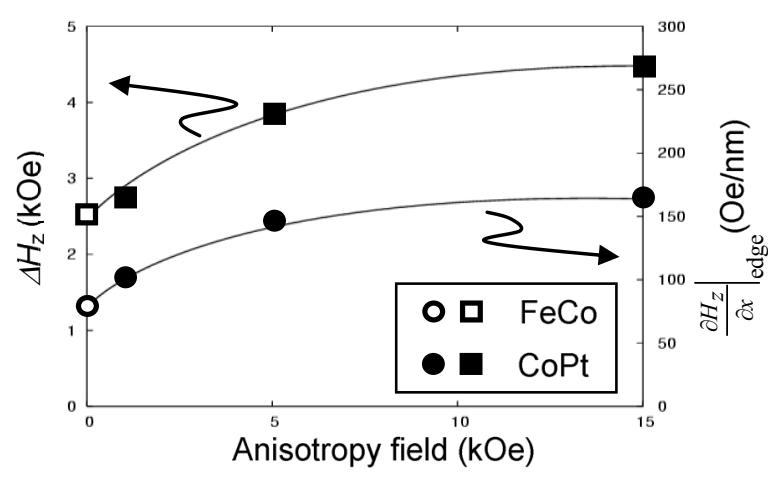

Fig. 5 Anisotropy field dependence of the peak-to-valley value of perpendicular component of recording field $\Delta H_{z}$ and recording field gradient $\partial H_{z} /\left.\partial x\right|_{\text {edge }}$ at the edge of the patterned magnetic film.

異方性磁場 $H_{\mathrm{k}}$ 依存性を示す. なお, 転写磁場は $5 \mathrm{kOe}$ とした. Fig. 5 より,$H_{\mathrm{k}}$ が高くなるに伴い, $\Delta H_{\mathrm{z}}$ 及び $\partial H_{\mathrm{z}} /\left.\partial x\right|_{\text {edge }}$ が増大寸るこ とがわかる. $H_{\mathrm{k}}=15 \mathrm{kOe}$ の $\mathrm{CoPt}$ 磁性膜の場合, $\mathrm{FeCo}$ 磁性膜に比 へ, $\Delta H_{\mathrm{z}}$ は 1.8 倍, $\partial H_{\mathrm{z}} /\left.\partial \mathrm{x}\right|_{\text {edge }}$ は 2.1 倍となっている. $\Delta H_{\mathrm{z}}$ の $H_{\mathrm{k}}$ 依存性について考察する。 $\Delta H_{\mathrm{z}}$ の振る舞いは, 印加磁場及 び反磁場の和と異方性磁場の大小関係で説明できると考え られる. 本シミュレーションで用いたマスター磁性膜の反 磁場係数は約 0.6 であり, マスター磁性膜磁化が飽和する とき, $\mathrm{CoPt}$ 磁性膜中心部近傍における反磁場は約 $10 \mathrm{kOe}$ である. 従って, 反磁場と転写磁場の和は $5 \mathrm{kOe}$ 程度であ り，このことから $\mathrm{CoPt}$ 磁性膜磁化を転写磁場印加方向に 向けるためには, 少なくとも $5 \mathrm{kOe}$ 程度以上の異方性磁場 が必要であると推定される. Fig. 5 の計算結果を見ると， $\Delta H_{\mathrm{z}}$ は, $H_{\mathrm{k}}$ が $5 \mathrm{kOe}$ 以上でほぼ飽和しており, CoPt 磁性膜 の磁化が転写磁場印加方向を向いていることが示唆され る.

\section{2 転写磁場が記録磁場及び転写特性に及ぼす影響}

転写磁場を 0 5 kOe の範囲で変化させたときの $\mathrm{CoPt}\left(H_{\mathrm{k}}\right.$ $=15 \mathrm{kOe}$ )マスターにおける記録磁場分布を Fig. 6 に示す. Fig. 6 より, 記録磁場分布の形は, 転写磁場にほとんど依 存しないことがわかる. 転写磁場を印加していない場合 $(0$ Oe)における記録磁場分布に注目すると，有限な $\Delta H_{\mathrm{z}}$ が生 じていることがわかる。ここで，スレーブ媒体の核生成磁 場は $2 \mathrm{kOe}$ 程度であるため, 転写磁場が $0 \mathrm{Oe}$ の場合におけ る記録磁場が，スレーブ磁化に影響を及ぼすことが考えら れるが，転写プロセスを考慮すると，この影響は無視でき る.この理由について説明する.まず, 一方向に初期磁化 したスレーブ媒体に，マスター媒体を接触させると, Fig. 6 の転写磁場 $0 \mathrm{Oe}$ の記録磁場が生じ，これにより，マスター 凸部と接触しているスレーブの磁化がわずかに反転する. 一方，マスターと接触していない部分の磁化状態は変わら ない. その後, 転写磁場を印加すると, マスター凸部と接 触している部分には強い記録磁場が印加され, スレーブの 磁化は更に大きく反転し, マスターと接触していない部分
の磁化はわずかに反転する.また，転写磁場を取り去ると き，及びマスターを引き剥がすときは，スレーブの磁化は， ヒステリシスループにおける横軸にほぼ平行なマイナール 一プに沿うため，転写磁場印加時の磁化がそのまま残る. 次に, 4.1 節での考察を基に $\operatorname{CoPt}\left(H_{\mathrm{k}}=5 \mathrm{k}, 6 \mathrm{k}\right.$ 及び 15 $\mathrm{kOe})$ における $\Delta H_{\mathrm{z}}$ 及び $\partial H_{\mathrm{z}} /\left.\partial \mathrm{x}\right|_{\mathrm{edge}}$ の転写磁場依存性を Fig. 7 に示寸. Fig. 6 に示される記録磁場分布の形状は, 転 写磁場強度に依存しないため, Fig. 7 における $H_{\mathrm{k}}=15 \mathrm{kOe}$ の $\mathrm{CoPt}$ 磁性膜では, $\Delta H_{\mathrm{z}}$ 及び $\partial H_{\mathrm{z}} /\left.\partial \mathrm{x}\right|_{\mathrm{edge}}$ 共に転写磁場に ほとんど依存しない. 次に, $H_{\mathrm{k}}=5 \mathrm{kOe} の \mathrm{CoPt}$ 磁性膜に着 目すると, 0 及び $2 \mathrm{kOe}$ の転写磁場を印加した場合の磁化が 垂直方向をあまり向いていないため，記録磁場分布の形状 は, Fig. 6 の分布と大きく異なる. 一方, 転写磁場が $3 \mathrm{k} \sim 5$ $\mathrm{kOe}$ の範囲での記録磁場分布の形状は Fig. 6 の形状に類似 している. それゆえ, Fig. 7 中の $H_{\mathrm{k}}=5 \mathrm{kOe}$ のグラフでは, 転写磁場が $3 \mathrm{kOe}$ 以上のものの夕を示している.また, $H_{\mathrm{k}}$ $=6 \mathrm{kOe}$ の場合, 転写磁場が 0 Oe の場合のみ, Fig. 6 の形 状と異なる記録磁場分布となり, $2 \mathrm{kOe}$ 以上の転写磁場で は Fig. 6 の形状と同様の分布が得られる. それゆえ, Fig. 7 中の $H_{\mathrm{k}}=6 \mathrm{kOe}$ のグラフでは, 転写磁場が $2 \mathrm{kOe}$ 以上のも のを示している. 以上より， $H_{\mathrm{k}}$ が約 $6 \mathrm{kOe}$ 以上であれば, 転写磁場を印加しない場合を除いては，ほぼ転写磁場依存 性がなくなることがわかる。転写特性を評価するために， Fig. 8 に示すようなヒステリシスループを持つスレーブ媒 体を想定した．スレーブ媒体の保磁力は $4 \mathrm{kOe}$, 保磁力付 近のループの傾き $\alpha$ は 2.8 である. 計算により得られた記 録磁場分布を用いて，このヒステリシスループをなぞるこ とにより $\Delta M_{\mathrm{z}} / M_{\mathrm{s}}$ を算出した. $\Delta M_{\mathrm{z}}$ は，転写されたスレーブ 媒体における垂直成分磁化の最大值と最小值の差であり, $\Delta M_{\mathrm{z}} / M_{\mathrm{s}}$ が 2 とは, スレーブの逆向き磁化がいずれも飽和值 になっていることを示す. $\Delta M_{\mathrm{z}} / M_{\mathrm{s}}$ を用いて $\operatorname{CoPt}\left(H_{\mathrm{k}}=15\right.$ $\mathrm{kOe})$ 及び $\mathrm{FeCo}$ 磁性膜の転写特性を比較した. $\Delta M_{\mathrm{z}} / M_{\mathrm{s}}$ の転 写磁場依存性を Fig. 9 に示 す. FeCo 磁性膜に注目すると, 転写磁場が $4 \mathrm{kOe}$ のとき, $\Delta M_{\mathrm{z}} / M_{\mathrm{s}}$ が最大となっていること

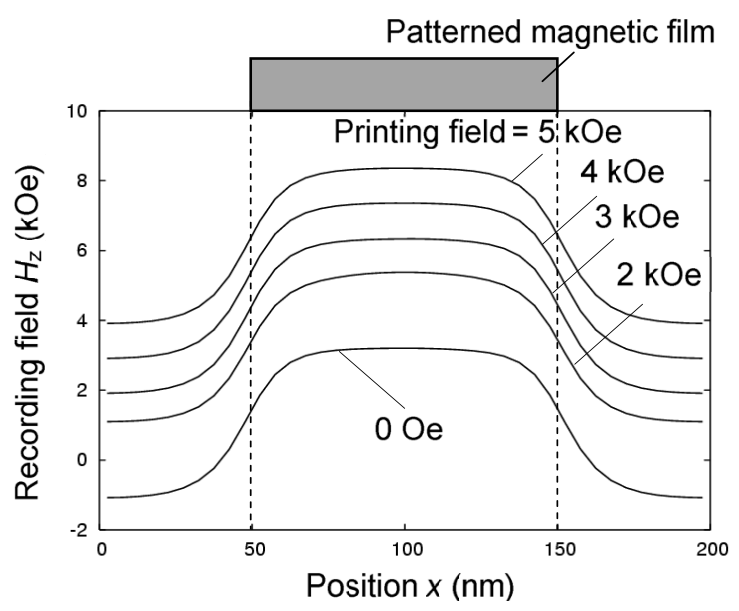

Fig. 6 Perpendicular component of the recording field distributions at the center of the track in various printing fields in the case of $\operatorname{CoPt}\left(H_{\mathrm{k}}=15 \mathrm{kOe}\right)$. 


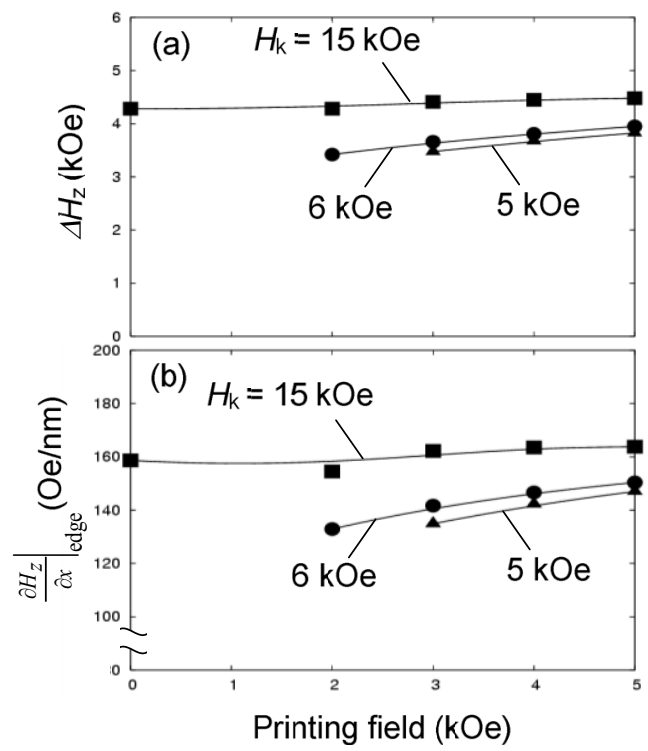

Fig. 7 Printing field dependence of the peak-to-valley value of the perpendicular component of the recording field $\Delta H_{\mathrm{z}}(\mathrm{a})$ and recording field gradient $\partial H_{\mathrm{z}} /\left.\partial \mathrm{x}\right|_{\text {edge }}$ at the edge of the magnetic pattern of a master (b).

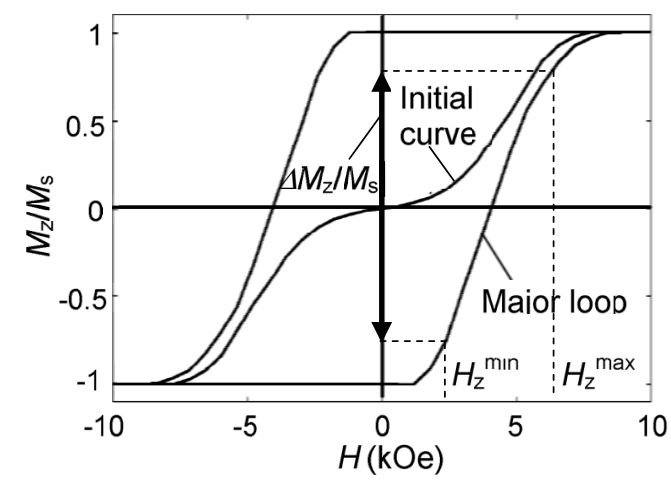

Fig. 8 Hysteresis loop of the recording layer in the perpendicular direction.

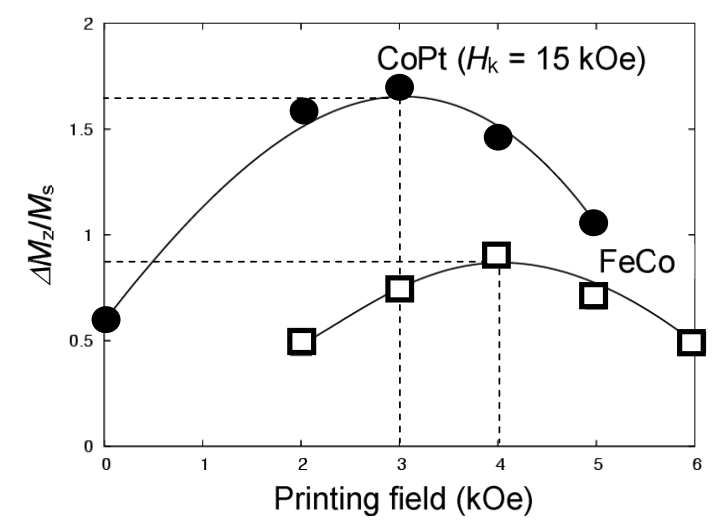

Fig. 9 Printing field dependence of the printing characteristics (CoPt and FeCo).
がわかる.これは，以前の研究結果と一致している ${ }^{3)}$. 次に $\mathrm{CoPt}$ 磁性膜に注目すると, 転写特性の最大值は 1.7 となっ ており, FeCo 磁性膜の最大值 0.8 と比べて, 2 倍強に向上し ていることがわかる.また，このときの転写磁場は $3 \mathrm{kOe}$ であり, $\mathrm{FeCo}$ 磁性膜の最適転写磁場に比べ, $1 \mathrm{kOe}$ 減少し ていることがわかる．以上のことから，マスター磁性膜に (大きな垂直磁気異方性を持つ) CoPt を用いることで，転写 特性の向上と，最適転写磁場の低減が可能であることが明 らかになった。

\section{5. まとめ}

本研究では，垂直磁気異方性を有するマスター媒体(PAMM)を 提案した. マイクロマグネティックシミュレーションにより PAMM 磁生膜内の磁化分布及び記録磁場分布を解析し，マスター 磁生膜に FeCoを用いた従来マスター媒体との比較を行った. その 結果, 次のことが明らかになった.

1. PAMM の異方性磁場が大きくなるに伴い, 記録磁場の最大 值が増大した. また, 記録磁場における peak-to-valley值及び マスター磁性膜エッジ部における記録磁場勾配が増大寸るこ とがわかった.

2. 大きな $H_{\mathrm{k}}$ を持つPAMM における, 記録磁場の車云写磁場依存 性を調べたところ, 転写磁場が 0 5 kOe の範囲では記録磁場 分布, peak-to-valley值及びマスター磁生膜エッジ部における 記録磁場勾配はほとんど変化しなかった。

3. PAMM 及び従来マスター媒体の転写特性を比較したところ, 従来マスター媒体に比べて PAMM の転写特性が 2 倍程度向 上し, PAMM の最適転写磁場は従来マスター媒体に比べ, 1 $\mathrm{kOe}$ 程度低くなることがわかった。

以上の結果, 垂直磁気転写に PAMM を用いることで, 転写特性の 更なる改善が可能であることが明らかになった。

謝辞 本研究の一部は, 新エネルギー・産業技術総合開発 機構(NEDO)産業技術研究助成事業の支援により行われま した．また，富士フイルム(株)の皆様には有益なご議論を 頂きました.ここに深謝致します.

\section{References}

1) M. Nishikawa, S. Wakamatsu, K. Ichikawa, T. Usa, M. Nagao, T. Ishioka, T. Yasunaga, T. Komine and R. Sugita: IEEE Trans. Magn., 42, 2612 (2006).

2) T. Murata, A. Izumi, T. Komine and R. Sugita: J. Magn. Soc. Jpn., 31, 58 (2007).

3) A. Izumi, Y. Nagahama, T. Komine, R. Sugita and T. Muranoi: J. Magn. Soc. Jpn., 30, 184 (2006).

4) M. Nakazawa, T. Komine and R. Sugita: J. Magn. Soc. Jpn., 32, 466 (2008).

2008年10月14日受理， 2009年1月9日採録 